\title{
Antiarrhythmics in patients with out-of-hospital-cardiac arrest do not improve survival to hospital discharge
}

\author{
Robert Allen ${ }^{1}$

${ }^{1}$ Corresponding author. Kings County Hospital Center (New York); SUNY Downstate Health Sciences University (New York). United States of America. robert.allen@downstate.edu 2Jackson South Medical Center (Miami). Florida, United States of America. ptepler@gmail.com ${ }^{3}$ Kings County Hospital Center (New York); SUNY Downstate Health Sciences University (New York). United States of America. ian.desouza@downstate.edu

\begin{tabular}{|l|l|}
\hline NNT Color recommendation & Red (potential benefits do not exceed harms) \\
\hline Summary Heading & $\begin{array}{l}\text { Antiarrhythmics for out-of-hospital cardiac arrest do not increase the } \\
\text { chance of survival to hospital discharge or survival to hospital discharge } \\
\text { with favorable neurologic outcome }\end{array}$ \\
\hline Benefits in NNT & No one was helped \\
\hline Benefits in Percentages & No one was helped \\
\hline Harms in NNT (NNH) & Not reported \\
\hline Harms in Percentages & Not reported \\
\hline Efficacy Endpoints & Survival to hospital discharge with favorable neurologic outcome, survival \\
& to hospital discharge, return of spontaneous circulation \\
\hline Harm Endpoints & Not reported \\
\hline Who was in the studies & 6,525 adults in 14 randomized controlled trials \\
\hline
\end{tabular}

\section{Narrative}

The International Liaison Committee on Resuscitation guidelines ${ }^{1}$ support the use of antiarrhythmics in patients with shock-resistant out-of-hospital cardiac arrest (OHCA), largely based on a systematic review and meta-analysis by Ali et al. 2 , the basis of this evidence summary. 
Ali et al.. found 14 randomized trials ( $n=6525$ subjects) on the use of antiarrhythmics in adult cardiac arrest. Upon meta-analysis, they found no significant difference with an antiarrhythmic agent compared to placebo in the patient-centered outcome of survival to hospital discharge: amiodarone (relative risk [RR] $1.1,95 \%$ confidence interval [CI] 0.98-1.3; $n=2530$ ), lidocaine (RR1.1,95\% Cl, 0.96-1.3; $\mathrm{n}=2041$ ), magnesium (RR 1.1, 95\% Cl 0.6-1.9; $\mathrm{n}=437$ ), and bretylium (RR 4.3, 95\% Cl 0.6-30.3; $\mathrm{n}=29$ ). The results were similar for survival to discharge with favorable neurologic outcome. However, there was a statistically increased return of spontaneous circulation associated with lidocaine (RR 1.2, 95\% Cl 1.0-1.3; $\mathrm{n}=2051$ ).

\section{Caveats}

The systematic review by Ali et al. .2 is comprehensive, yet the results should be interpreted with caution. Ali et al noted risks of bias among included studies such as issues with randomization, improper allocation concealment and blinding, baseline imbalance, failure to adhere to intention-to-treat analysis, and industry funding. They therefore rated the evidence "very low to moderate certainty."

Twelve of 14 trials were also performed before 2005, and there have since been revisions of guidelines and advancements in care including increases in bystander CPR, implementation of targeted temperature management, and greater use of postarrest coronary catheterization ${ }^{3}$. For instance in the 2016 ROC-ALPS trial", significant proportions received targeted temperature management (74\%) and coronary catheterization (56\%), and the placebo group survival rate was 21\%. In the 1999 Kudenchuk et al. trial ${ }^{5}$, such procedures were uncommon, and the placebo group survival rate was $13 \%$. The inclusion of older trials may therefore limit the applicability of this meta-analysis to contemporary clinical practice.

The timing of drug administration may also help to explain the absence of meaningful benefit found in

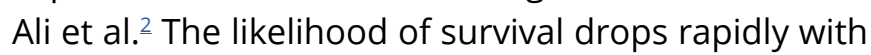
time after cardiac arrest ${ }^{6}$, and antiarrhythmic drugs may function best within ten minutes of arrest the 'metabolic' phase ${ }^{\mathrm{z}}$. This theory is supported by an analysis of a subgroup with witnessed arrest in Kudenchuk et al. ${ }^{4}$. In this subgroup $(n=1934)$, drug administration presumably took place earlier after arrest and more frequently within the metabolic phase. A statistically significant increase in survival to discharge with both amiodarone $(27.7 \%)$ and lidocaine (27.8\%) compared to placebo (22.7\%). However, these subgroup findings are, at best, hypothesis-generating.

In summary, we assign a recommendation of 'Red' (benefits do not outweigh harms) for antiarrhythmic administration in cardiac arrest with a shockable rhythm. There is no overall evidence of patientcentered benefit. There is, however, a signal that earlier administration of antiarrhythmics in patients with witnessed arrest may be beneficial, and we hope future studies will address this possibility.

\section{Author contributions}

RA drafted the manuscript, and all authors contributed substantially to its revision. RA takes responsibility for the paper as a whole.

\section{Competing interests}

No financial, legal or political competing interests with third parties (government, commercial, private foundation, etc.) were disclosed for any aspect of the submitted work (including but not limited to grants, data monitoring board, study design, manuscript preparation, statistical analysis, etc.).

\section{References}

\begin{abstract}
1. Soar J, Donnino MW, Maconochie I, Aickin R, Atkins $\mathrm{DL}$, Andersen LW et al. 2018 International consensus on cardiopulmonary resuscitation and emergency cardiovascular care science with treatment recommendations summary. Circulation. 2018;138(23):714-30. doi: $10.1161 /$ CIR.0000000000000611
\end{abstract}

2. Ali MU, Fitzpatrick-Lewis D, Kenny M, Raina P, Atkins DL, Soar J, et al. Effectiveness of antiarrhythmic drugs for shockable cardiac arrest: A systematic review. Resuscitation. 2018;132:63-72. doi: $\underline{10.1016 / j . \text {.resuscitation.2018.08.025 }}$

3. Riva G, Ringh M, Jonsson M, Svensson L, Herlitz J, Claesson A et al. Survival in out-of-hospital cardiac arrest after standard cardiopulmonary resuscitation or chest compressions only before arrival of emergency medical services: nationwide study during three guideline periods. Circulation. 2019;139(23):2600-9. doi: 10.1161/CIRCULATIONAHA.118.038179 
4. Kudenchuk PJ, Brown SP, Daya M, Rea T, Nichol G, Morrison LJ et al. Amiodarone, lidocaine, or placebo in out-of-hospital cardiac arrest. N Engl J Med. 2016;374(18):1711-22. doi: 10.1056/ NEJMoa1514204

5. Kudenchuk PJ, Cobb LA, Copass MK, Cummins RO, Doherty AM, Fahrenbruch $\mathrm{CE}$ et al. Amiodarone for resuscitation after out-ofhospital cardiac arrest due to ventricular fibrillation. N Engl J Med. 1999;341(12):871-8. doi: 10.1056/NEJM199909163411203
6. Larsen MP, Eisenberg MS, Cummins RO, Hallstrom AP.

Predicting survival from out-of-hospital cardiac arrest: a graphic model. Ann Emerg Med. 1993;22(11):1652-8. doi: 10.1016/s01960644(05)81302-2

7. Weisfeldt ML, Becker LB. Resuscitation after cardiac arrest: a 3-phase time-sensitive model. JAMA. 2002;288(23):3035-8. doi: 10.1001/jama.288.23.3035 